\section{Trauma Surgery} \& Acute Care Open

Division of General Surgery, Department of Surgery, University of Toronto, Toronto, Ontario, Canada

${ }^{2}$ Li Ka Shing Knowledge Institute, St Michael's Hospital, Toronto, Ontario, Canada

\section{Correspondence to} Dr Graham Skelhorne-Gross, Li Ka Shing Knowledge Institute, St. Michael's Hospital, Toronto, ON M5B 1W8, Canada; graham. skelhornegross@mail.utoronto. ca

Received 28 September 2018 Revised 11 December 2018 Accepted 18 December 2018

(C) Author(s) (or their employer(s)) 2019. Re-use permitted under CC BY-NC. No commercial re-use. See rights and permissions. Published by BMJ.

To cite: Skelhorne-Gross $\mathrm{G}$, Gomez D. Trauma Surg Acute Care Open 2019:4:e00243.

\title{
Perforated appendicitis in the setting of a massive ventral hernia, morbid obesity, and multiple severe comorbidities: challenges in acute management
}

\author{
Graham Skelhorne-Gross, ${ }^{1}$ David Gomez ${ }^{1,2}$
}

\section{CASE SUMMARY}

A 57-year-old woman with morbid obesity (body mass index [BMI] of 43), systemic lupus on steroids, type 2 insulin-dependent diabetes, peripheral vascular disease, unprovoked pulmonary embolism on rivaroxaban, and hypertension presented with 3 days of worsening abdominal pain and nausea. She had an extensive surgical history including a cesarean section, multiple laparotomies for small bowel obstructions (one complicated by bowel perforation requiring resection), and a double-barrelled ileostomy, which had been since reversed. As a result, she had a massive incisional hernia (figure 1). On presentation she was afebrile but tachycardic at 110 beats per minute. Physical examination revealed tenderness to deep palpation in the right upper and lower quadrants. CT demonstrated an $11 \mathrm{~mm}$ appendix with an appendicolith outside the hernia sac abutting the right kidney, discontinuity of the appendix tip, free fluid, and associated stranding in the subhepatic region (figure 2A). She was admitted to the surgical floor for a trial of conservative management with ancef and flagyl. On day 3, her pain worsened, her white cell count remained stable at $12 \times 10^{9} / \mathrm{L}$, her temperature

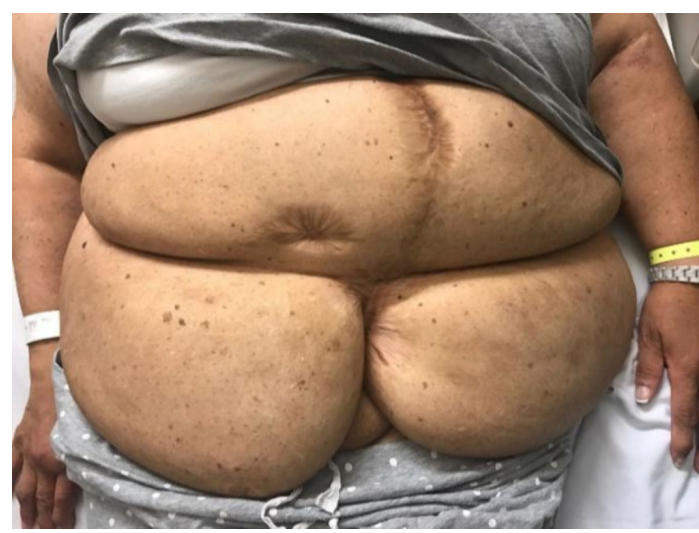

Figure 1 Patient's abdomen demonstrating midline laparotomy incisional scar, previous ileostomy scar, and massive ventral hernia.

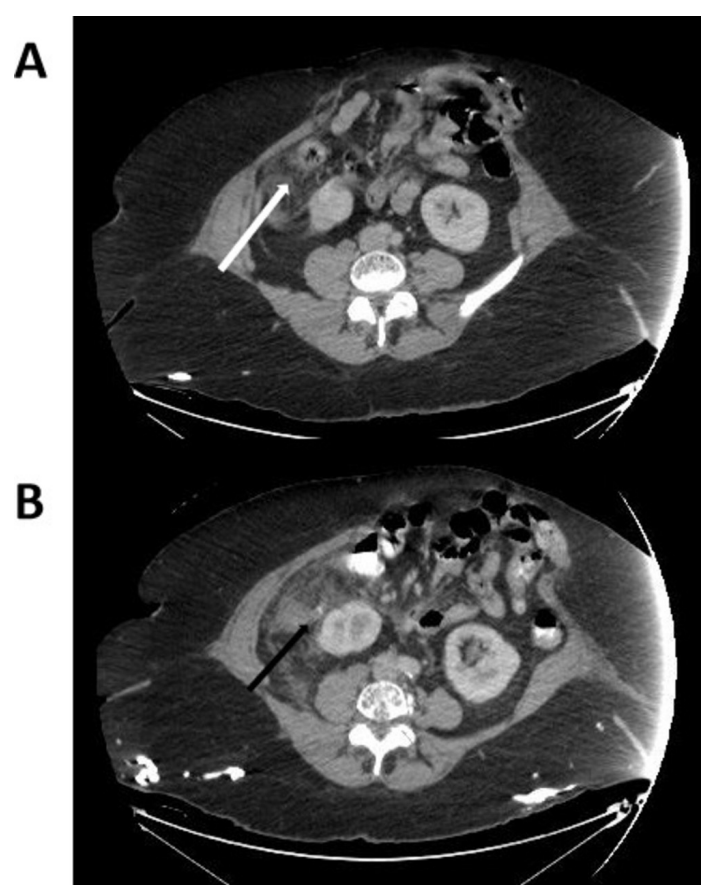

Figure 2 Abdominal CT showing increased stranding centered around the appendix, with discontinuity of the wall of the appendix tip and free fluid within the abdomen and pelvis. (A) Admission CT. White arrow: appendix. (B) CT on postadmit day 3 as patient worsened clinically. Black arrow: fecalith.

was $37.8^{\circ} \mathrm{C}$, she was not tachycardic, and a repeat CT showed a $15 \mathrm{~mm}$ perforated appendix with increased periappendiceal stranding and an associated small volume of free fluid. There was no phlegmon or organized abscess (figure 2B).

\section{WHAT WOULD YOU DO?}

1. Continue non-operative management with broadened intravenous antibiotic coverage and bowel rest.

2. Laparoscopic \pm open appendectomy without concomitant hernia repair.

3. Laparoscopic \pm open appendectomy with abdominal wall reconstruction. 


\section{WHAT WE DID AND WHY}

We elected not to operate in the emergent setting, given that our patient had a potentially hostile abdomen, multiple severe comorbidities, and most importantly no signs of severe sepsis. She was kept nil per os and treated with piperacillin-tazobactam until she was tolerating oral medication when she received Clavulin. Her abdominal discomfort improved during the next 48 hours, and she was discharged home after 1 week.

An elective interval appendectomy and ventral hernia repair with a Strattice underlay 5 weeks after discharge was performed. Her interval appendectomy was performed 6 weeks after presentation, which is consistent with published recommendations. ${ }^{1-3}$ The operation was technically challenging requiring over 6 hours to complete. Fortunately, her postoperative course has been unremarkable.

Most studies on acute uncomplicated appendicitis suggest that surgical management is superior to medical management. ${ }^{4-7}$ However, patients with multiple comorbidities, especially systemic illness or steroid usage, ${ }^{89}$ or those with complicated appendicitis, ${ }^{10}$ have been excluded from several of these trials. Therefore, we were cautious about extrapolating from their data to predict outcomes in our patient.

There is substantial evidence that comorbid patients receiving appendectomy suffer worse outcomes. Postoperatively, obese patients have increased rates of wound infection (5.5\% vs. $3.8 \%)$ and pneumonia ( $1 \%$ vs. $0.3 \%) .{ }^{11}$ As BMI increases, so does the risk of incisional hernia at the port sites for laparoscopic surgery. ${ }^{12}$ The overall rate of incisional hernia is approximately 6\%; however, this incidence triples to $18 \%$ in morbidly obese patients. ${ }^{12}$ Patients with a BMI greater than 30 are significantly more likely to develop an intra-abdominal abscess. ${ }^{13}$ This could be due to the technical challenges associated with operating on obese patients or be a consequence of immunosuppression secondary to concomitant comorbidities such as diabetes. ${ }^{13}$ Patients with diabetes require longer postoperative stays in hospital ( 3 days vs. 1 day for non-diabetics) as they are more than twice as likely to suffer complications such as ileus, surgical site infection, or pneumonia (19\% vs. $6 \%) .{ }^{14}$ Finally, systemic steroid usage increases the likelihood of developing sepsis as well as increases the 30-day perioperative mortality after appendectomy. ${ }^{15}$ Given the aforementioned perioperative risks for patients with these comorbidities, as well as the predicted hostility of her abdomen, we thought that a conservative approach was most appropriate.

Despite the traditional viewpoint that complicated appendicitis warrants urgent surgical treatment, ${ }^{31617}$ several groups have shown that complicated appendicitis can be safely managed conservatively. In a meta-analysis of complicated appendicitis, medical management produced fewer overall complications, wound infections, abdominal/pelvic abscesses, and ileus/bowel obstructions. Further, there were no differences in the duration of hospitalization or antibiotic treatment required. ${ }^{2}$ A separate study showed that the odds of any complication were $78 \%$ lower in patients treated conservatively, whereas the chance of developing an ileus or intra-abdominal abscess was equivalent between patients treated surgically or medically. ${ }^{18}$ Another meta-analysis looking at appendiceal abscess/phlegmon treatment found increased morbidity after surgical management, with an OR of 3.3 (CI 1.9 to 5.6). ${ }^{19}$ Non-surgical management was effective in $93 \%$ of patients. ${ }^{19}$ Others have described similar efficacy of conservative treatment but noted that many patients who failed conservative management required major bowel resections. ${ }^{17}$

The recurrence rate after conservative management for uncomplicated appendicitis is approximately $34 \%$ at 2 years and
$39 \%$ at 5 years. ${ }^{20}$ Another important consideration is the risk of malignancy. The incidence of malignancy has been estimated to be approximately $1 \%$ overall. However, the risk increases with age, and recent literature suggests the rate of malignancy is higher in complicated appendicitis. ${ }^{21}$

In summary, patients with complicated appendicitis do not always require immediate surgical management; decisions should include a thoughtful evaluation of their individualized perioperative risks. Non-operative management can be feasible and safe under close monitoring. In addition, interval appendectomy should be strongly considered once the patient can be optimized, particularly in patients older than 40 .

Contributors GS-G wrote the article and performed the required literature search. DG conceived of the idea for the topic and edited the article.

Funding The authors have not declared a specific grant for this research from any funding agency in the public, commercial or not-for-profit sectors.

Competing interests None declared.

Patient consent for publication Obtained.

Provenance and peer review Not commissioned; externally peer reviewed.

Open access This is an open access article distributed in accordance with the Creative Commons Attribution Non Commercial (CC BY-NC 4.0) license, which permits others to distribute, remix, adapt, build upon this work non-commercially, and license their derivative works on different terms, provided the original work is properly cited, appropriate credit is given, any changes made indicated, and the use is non-commercial. See: http://creativecommons.org/licenses/by-nc/4.0/.

\section{REFERENCES}

1. Andersson RE, Petzold MG. Nonsurgical treatment of appendiceal abscess or phlegmon: a systematic review and meta-analysis. Ann Surg 2007;246:741-8.

2. Simillis C, Symeonides P, Shorthouse AJ, Tekkis PP. A meta-analysis comparing conservative treatment versus acute appendectomy for complicated appendicitis (abscess or phlegmon). Surgery 2010;147:818-29.

3. Cheng Y, Xiong X, Lu J, Wu S, Zhou R, Cheng N. Early versus delayed appendicectomy for appendiceal phlegmon or abscess. Cochrane Database Syst Rev 2017:6:CD011670.

4. Harnoss JC, Zelienka I, Probst P, Grummich K, Müller-Lantzsch C, Harnoss JM, Ulrich A, Büchler MW, Diener MK. Antibiotics versus surgical therapy for uncomplicated appendicitis: systematic review and meta-analysis of controlled trials (prospero 2015: CRD42015016882). Ann Surg 2017;265:889-900.

5. Sakran JV, Mylonas KS, Gryparis A, Stawicki SP, Burns CJ, Matar MM, Economopoulos KP. Operation versus antibiotics--The "appendicitis conundrum" continues: A metaanalysis. J Trauma Acute Care Surg 2017;82:1129-37.

6. Podda M. ACOI (Italian Society of hospital Surgeons) Study Group on acute appendicitis Antibiotics-first strategy for uncomplicated acute appendicitis in adults is associated with increased rates of peritonitis at surgery. A systematic review with meta-analysis of randomized controlled trials comparing appendectomy and non-operative management with antibiotics. Surgeon 2017:1-12.

7. Huston JM, Kao LS, Chang PK, Sanders JM, Buckman S, Adams CA, Cocanour CS, Parl SE, Grabowski J, Diaz J, et al. Antibiotics vs. appendectomy for acute uncomplicated appendicitis in adults: review of the evidence and future directions. Surg Infect 2017:18:527-35

8. Salminen P, Paajanen $H$, Rautio T, Nordström P, Aarnio M, Rantanen T, Tuominen R, Hurme S, Virtanen J, Mecklin JP, et al. Antibiotic therapy vs appendectomy for treatment of uncomplicated acute appendicitis: the APPAC randomized clinical trial. JAMA 2015:313:2340-8.

9. Vons C, Barry C, Maitre S, Pautrat K, Leconte M, Costaglioli B, Karoui M, Alves A, Dousset $B$, Valleur $P$, et al. Amoxicillin plus clavulanic acid versus appendicectomy for treatment of acute uncomplicated appendicitis: an open-label, non-inferiority, randomised controlled trial. The Lancet 2011;377:1573-9.

10. Styrud J, Eriksson S, Nilsson I, Ahlberg G, Haapaniemi S, Neovius G, Rex L, Badume I, Granström L. Appendectomy versus antibiotic treatment in acute appendicitis. A prospective multicenter randomized controlled trial. World J Surg 2006:30:1033-7.

11. Michailidou M, Sacco Casamassima MG, Goldstein SD, Gause C, Karim O, Salazar JH, Yang J, Abdullah F. The impact of obesity on laparoscopic appendectomy: results from the ACS national surgical quality improvement program pediatric database. J Pediatr Surg 2015:50:1880-4.

12. Buckley FP, Vassaur HE, Jupiter DC, Crosby JH, Wheeless CJ, Vassaur JL. Influencing factors for port-site hernias after single-incision laparoscopy. Hernia 2016:20:729-33.

13. Schlottmann F, Sadava EE, Peña ME, Rotholtz NA. Laparoscopic appendectomy: risk factors for postoperative intraabdominal abscess. World J Surg 2017:41:1254-8. 
14. Bach L, Donovan A, Loggins W, Thompson S, Richmond B. Appendicitis in diabetics: predictors of complications and their incidence. Am Surg 2016;82:753-8.

15. Margenthaler JA, Longo WE, Virgo KS, Johnson FE, Oprian CA, Henderson WG, Daley J, Khuri SF. Risk factors for adverse outcomes after the surgical treatment of appendicitis in adults. Ann Surg 2003;238:59-66.

16. Elkbuli A, Diaz B, Polcz V, Hai S, McKenney M, Boneva D. Operative versus nonoperative therapy for acute phlegmon of the appendix: is it safer? A case report and review of the literature. Int I Surg Case Rep 2018;50:75-9.

17. Young KA, Neuhaus NM, Fluck M, Blansfield JA, Hunsinger MA, Shabahang MM, Torres DM, Widom KA, Wild JL. Outcomes of complicated appendicitis: is conservative management as smooth as it seems? The American Journal of Surgery 2018;215:586-92.
18. Vaos G, Dimopoulou A, Gkioka E, Zavras N. Immediate surgery or conservative treatment for complicated acute appendicitis in children? A meta-analysis. J Pediatr Surg 2018.

19. Andersson R, Petzold M. Nonsurgical treatment of appendiceal abscess or phlegmon: a systematic review and meta-analysis. Ann Surg 2007;246:741-8.

20. Salminen P, Tuominen R, Paajanen H, Rautio T, Nordström P, Aarnio M, Rantanen T, Hurme S, Mecklin JP, Sand J, et al. Five-year follow-up of antibiotic therapy for uncomplicated acute appendicitis in the APPAC randomized clinical trial. JAMA 2018;320:1259-65.

21. Mällinen J, Rautio T, Grönroos J, Rantanen T, Nordström P, Savolainen H, Ohtonen $P$, Hurme S, Salminen P, Malinen MetA. Risk of appendiceal neoplasm in periappendicular abscess in patients treated with interval appendectomy vs follow-up with magnetic resonance imaging. JAMA Surg 2018. 